\title{
Simulation of Tillage Systems Impact on Soil Biophysical Properties Using the SALUS Model
}

\author{
Bruno Basso ${ }^{1,3^{*}}$, Joe T. Ritchie 2 , Peter R. Grace ${ }^{3}$, Luigi Sartori ${ }^{2}$ \\ ${ }^{1}$ Dipartimento di Scienze dei Sistemi Colturali, Forestali e dell'Ambiente, Università della Basilicata \\ Viale Ateno Lucano 10, 85100 Potenza, Italy \\ ${ }^{2}$ Department of Agricultural and Biosystem Engineering, University of Florida \\ Gainesville, Florida, USA \\ ${ }^{3}$ School of Natural Resources Sciences, Queensland University of Technology, Brisbane, Australia \\ ${ }^{4}$ Dipartimento Territorio e Sistemi Agro-Forestali, Università di Padova \\ Agripolis, Viale dell'Università 16, 35020 Legnaro (Pd), Italy
}

\begin{abstract}
A sustainable land management has been defined as the management system that allows for production, while minimizing risk, maintaining quality of soil and water. Tillage systems can significantly decrease soil carbon storage and influence the soil environment of a crop. Crop growth models can be useful tools in evaluating the impact of different tillage systems on soil biophysical properties and on the growth and final yield of the crops. The objectives of this paper were i) to illustrate the SALUS model and its tillage component; ii) to evaluate the effects of different tillage systems on water infiltration and time to ponding, iii) to simulate the effect of tillage systems on some soil biophysical properties. The SALUS (System Approach to Land Use Sustainability) model is designed to simulate continuous crop, soil, water and nutrient conditions under different tillage and crop residues management strategies for multiple years. Predictions of changes in surface residue, bulk density, runoff, drainage and evaporation were consistent with expected behaviours of these parameters as described in the literature. The experiment to estimate the time to ponding curve under different tillage system confirmed the theory and showed the beneficial effects of the residue on soil surface with respect to water infiltration. It also showed that the no-tillage system is a more appropriate system to adopt in areas characterized by high intensity rainfall.
\end{abstract}

Key-words: tillage systems, modeling, SALUS, ponding, carbon.

\section{Introduction}

Soil organic carbon (SOC) is the most often reported attribute from long-term studies and is chosen as the most important indicator of soil quality and agronomic sustainability because of its impact on other physical, chemical and biological indicators of soil quality (Reeves, 1997). A sustainable land management has been defined as the management system that allows for production, while minimizing risk, maintaining quality of soil and water. Long term studies have consistently show benefit of increasing $\mathrm{C}$ input into the soil. However, even with crop rotation and manure additions, continuous cropping results in a decline in SOC, although the rate and magnitude of the decline is affected by cropping and tillage systems, climate and soil
(Rasmussen et al., 1998). Restoring soil carbon is essential to enhancing soil quality, sustaining and improving food production, maintaining clean water, and reducing increase in atmospheric $\mathrm{CO}_{2}$ (Robertson et al., 2000; Bouma, 2002). Conventional agriculture, which includes practices such as crop residue burning or deep soil inversion by tilling, is generally harmful to the environment (Basso et al., 2002). These techniques considerably increase soil deformation by compaction, erosion and river contamination with sediments, fertilisers and pesticides. Such short-sighted farming practices have resulted in loss of an estimated $4 \pm 1$ gigatons of carbon from soils of the United States, and $7812 \mathrm{Gt}$ from the world's soils (Lal, 2004), a large fraction of which ended up in the atmosphere con- 
tributing to global warming and reduced the sustainability of agriculture by lowering soil organic matter and fertility, along with further negative environmental effects (e.g. a decrease in biodiversity). Conservation agriculture refers to several practices which permit the management of soil for agricultural uses, altering its composition, structure and natural biodiversity as little as possible and defending it from erosion and degradation (Basso et al., 2000; Basso, 2003). Conservation agriculture includes direct sowing/ no-tillage, reduced tillage/ minimum tillage, non - or surface- incorporation of crop residues and establishment of cover crops in both annual and perennial crops. Generally, with conservation agriculture the soil is protected from rainfall erosion and water runoff; the soil aggregates, organic matter and fertility level naturally increase, and soil deformation under heavy wheel load is reduced (Lal, 2004). Leaving crop residues after harvest increases the carbon content of soil, but the benefits are lost if the biomass is plowed under, because microorganisms quickly degrade residue $\mathrm{C}$ to $\mathrm{CO}_{2}$ (Reicosky et al., 1995; Borin et al., 1997) and essential nutrients that adhere to SOC disappear with its depletion. Thus, farmers require more fertilizer, irrigation and pesticide to preserve yield.

There is scientific evidence that soil tillage has been a significant component of the increase in atmospheric $\mathrm{CO}_{2}$ which has occurred in the last few decades (Lal, 1997). Historically, intensive tillage of agricultural soils has led to substantial losses of soil $\mathrm{C}$ that range from $30 \%$ to $50 \%$ (Davidoson, 1993). These $\mathrm{CO}_{2}$ losses are related to soil fracturing which facilitate the movement of $\mathrm{CO}_{2}$ out of the soil and oxygen into it (Reicoisky et al., 1997; Lal, 2004). Conventional agriculture operations (mouldboard ploughing) bury nearly all the residue and leave the soil in a rough, loose, and open condition resulting in maximum $\mathrm{CO}_{2}$ losses and a consistent reduction of the $\mathrm{CO}_{2}$ sink effect of the soil. The less we till, the more carbon we capture, store or sequester to build up organic matter and long-term productivity and, at the same time, the lesser the carbon dioxide that is released into the atmosphere (Cole, 1996; Paustian et al., 1998; Rasmussen et al., 1998; Smith et al., 1998).

A major concern among producers is the possible yield penalties associated with reduced tillage compared to conventional tillage. Residue cover on the soil surface reflects solar radiation and acts as an insulator, slowing soil warming during spring. This effect is more noticeable in a temperate, cool climate with wet and cool springs because high soil water content maintained by residue cover is combined with low energy income (Allmaras et al., 1977). Because of improved water infiltration and water conservation resulting from a residue cover, yields are improved in lower rainfall years and dry locations (Basso et al., 1996; Griffith et al., 1977). Reicosky et al. (1977) reported that on poorly drained soils, maize yields were decreased because poorly drained soils are usually colder due to higher water content. When vegetative maize development is delayed by lower temperature created by a residue cover, maize yield loss to short maturity due to short maturity period is more noticeable. Residue cover decreases the probability of water deficit by increasing water infiltration, through the reduction of the impact of rain on soil surface, and reducing evaporation.

Although the scientific knowledge of tillage effects on soil properties is rather extensive, models that account for tillage are few and their applications is limited. Crop growth models that account for management effects on yield and environmental impact can help farmers and policy makers make decisions because they provide output on crop response for a wide variety of environments and management inputs. In this regards, crop growth models can be useful tools in evaluating the impact of different tillage systems on the growth and final yield of the crops. There are existing models that account for tillage effects on soil properties but require either large input requirements or rather poor crop growth components. Dadoun (1993) developed CERES-Till, a model to predict the influence of crop residue cover on soil surface properties and plant development. Andales et al. (2000) incorporated CERES-Till into CROPGRO-Soybean. The model gave good predictions when compared to measured values for an Iowa case study.

The objectives of this paper were i) to illustrate the SALUS model and its tillage component; ii) to measure the effects of different tillage methods and residue management practices in a tropical environment on field infiltra- 
tion; iii) to use a time to ponding approach for predicting the rate of water infiltration into arable soils; iv) to simulate the effect of tillage systems on soil organic carbon, bulk density, drainage, soil evaporation and surface runoff.

\section{Methodology}

\subsection{Brief overview of the SALUS model}

The SALUS (System Approach to Land Use Sustainability) model is designed to simulate continuous crop, soil, water and nutrient conditions under different management strategies for multiple years (Figure 1). These strategies may have various crop rotations, planting dates, plant populations, irrigation and fertilizer applications, and tillage practices. The program simulates plant growth and soil conditions every day (during growing seasons and fallow periods) for any time period when weather sequences are available. For any simulation run, a number of different management strategies can be run simultaneously. By running the different strategies at the same time we can compare this effect on crops and soil under the same weather sequences. This also provides a framework whereby the interaction between different areas under different management practices can be easily be compared. Every day, and for each management strategy being run, all major components of the crop-soil-water model are executed. These components are management practices, water balance, soil organic matter, nitrogen and phosphorous dynamics, heat balance, plant growth and plant development. The water balance considers surface runoff, infiltration, surface evaporation, saturated and unsaturated soil water flow, drainage, root water uptake, soil evaporation and transpiration. The soil organic matter and nutrient model simulates organic matter decomposition, $\mathrm{N}$ mineralization and formation of ammonium and nitrate, $\mathrm{N}$ immobilization, gaseous $\mathrm{N}$ losses and three pools of phosphorous. The development and growth of plants uses temperature and light to calculate the potential rates of growth for the plant. This growth is then reduced based on water and nitrogen limitations.

The SALUS biophysical model is composed of three main structural components: i) a set of crop growth modules; ii) a soil organic matter and nutrient cycling module and; iii) a soil water balance and temperature module.

The crop growth modules are derived from the CERES (Ritchie et al., 1985; Ritchie et al., 1989) and IBSNAT family of crop production models (Jones and Ritchie, 1991) that were originally developed for single year, monoculture simulations. The crop growth algorithms from these were extracted and restructured into crop growth modules that are linked to the soil water, nutrient and management submodels. Current operational crop growth modules include maize and wheat. Rice, barley, sorghum and millet simulation modules are under development. A generic grain legume module (e.g., soybean, dry beans) and alfalfa growth modules are being added to the system. Phasic development is controlled by environmental variables (e.g., degree days, photoperiod) governed by varietyspecific genetic coefficients. Carbon assimilation

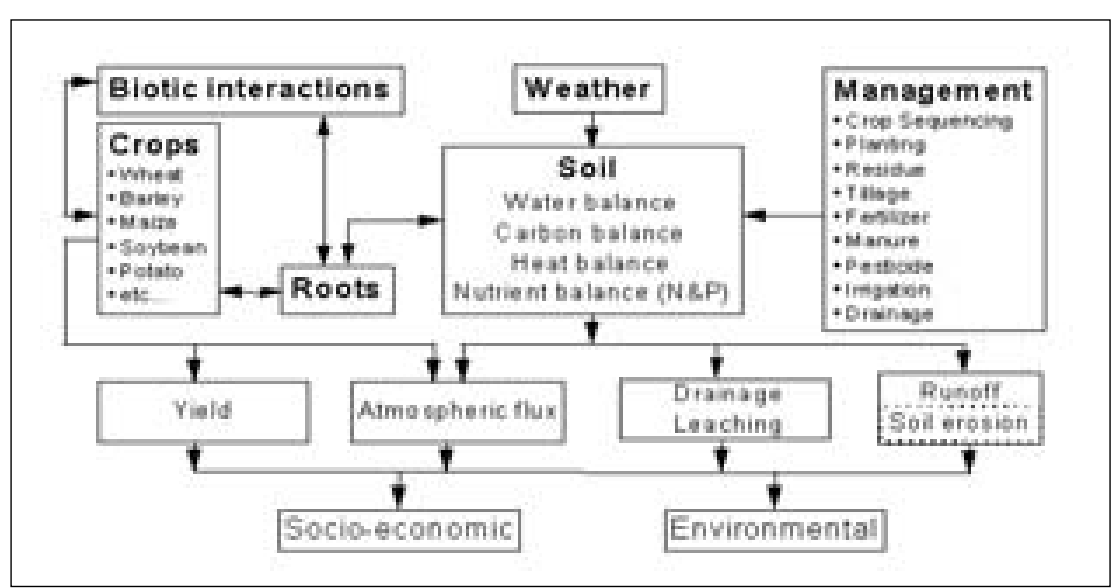

Figure 1. Diagram of the components of SALUS. 
and dry matter production are a function of potential rates (controlled by light interception and parameters defining the variety-specific growth potential) which are then reduced according to water and/or $\mathrm{N}$ limitations. The main external inputs required for the crop growth routines are the genetic (variety-specific) coefficients and daily solar radiation as a driving variable.

The soil organic matter (SOM) and nitrogen module is derived from the Century model with a number of modifications incorporated. The model simulates organic matter and $\mathrm{N}$ mineralization/immobilization from three SOM pools (active, slow and passive) which vary in their turnover rates and characteristic $\mathrm{C} / \mathrm{N}$ ratios. There are two crop residue/fresh organic matter pools (structural and metabolic), for representing recalcitrant and easily decomposable residues, based on residue lignin and $\mathrm{N}$ content. A surface active SOM pool associated with the surface residue pools was added to better represent conservation tillage systems and perennial crops. The soil phosphorous $(\mathrm{P})$ model incorporates inorganic and organic phosphorous dynamics. Inorganic $\mathrm{P}$ is divided into three pools i) labile; ii) active; and iii) stable.

The soil water balance module is based on that used in the CERES models but incorporates a major revision in calculating infiltration, drainage, evaporation and runoff. In SALUS, a time-to-ponding (TP) concept is used (see section 2.3 for details) to replace the previous runoff and infiltration calculations which were based on SCS runoff curve numbers.

The SALUS model does not explicitly include submodels to predict pest and disease outbreaks or the occurrence of extreme weather events (e.g., hail). We recognize that these factors can have a major impact on crop production and yield and the sustainability of a particular management system. However, the multitude of potential pest species and disease-causing organisms of major crop species precludes the inclusion of pest dynamics submodels explicitly within a general cropping systems model such as SALUS. Similarly, it is unrealistic to attempt to predict the occurrence of extreme weather events within the model structure. Simulation using the SALUS can also be performed on the web-based system. SALUS-web version was developed by the GIS centre of the Feng
Chia University in Taiwan and it is available to the public at http://salus.gis.fcu.edu.tw.

\subsection{Salus tillage and residue component}

The tillage model present in SALUS was based on CERES-Till (Dadoun, 1993), a model used to predict the influence of crop residue cover and tillage on soil surface properties and plant development. The model requires tillage date, tillage implement and tillage depth. Shelton et al. (1990) and Buckingham and Pauli (1993) proposed to use the product of percent of residues remaining after tillage operation as a way to calculate final residue biomass at the surface. Values of percentage of remaining residue at the surface are estimated from the tillage tools used. Low and high limits are given in table 1 as the amount incorporated increases with residues breakability. Multiplying the coefficients for each tillage operation provides an estimate of the percentage of residues left at the surface.

2.2.1 Residue coverage. The fraction of the soil surface covered by the remaining residue $(\mathrm{Fc})$ is calculated by:

$$
\mathrm{FC}=1.0-\operatorname{EXP}\left(-\mathrm{AM}^{*} \text { Mulch }\right)
$$

where $\mathrm{AM}$ is the area covered per unit dry weight of residue (ha kg-1) and is dependent on residue type (e.g. crop, density) and Mulch is the amount of surface residue remaining after tillage $\left(\mathrm{kg} \mathrm{ha}^{-1}\right)$. The equation is based on the probability of each piece of residue falling on a bare soil surface. Dadoun (1993) gives AM values for common crops (Table 2). FC is used in subsequent calculations for surface albedo and the effect of rainfall kinetic energy on surface soil properties.

Residue thickness is important in determining the reduction of soil evaporation due to surface residue. The algorithm for estimating average residue thickness assumes that the residues are arranged in layers, each layer one residue thick, with the coverage of each layer described by Eq. (1). The total thickness of the surface residues is calculated by summing the areaweighted thickness of each layer once all of the total residue biomass is accounted for.

2.2.2 Water balance effects. The presence of crop residues affects the soil water balance through rainfall interception and reduction in soil evap- 
Table 1. Residue incorporation percentage during common field operations (adapted from Buckingham and Pauli, 1993).

\begin{tabular}{|c|c|c|}
\hline \multirow[t]{2}{*}{ Operation } & \multicolumn{2}{|c|}{ Type of residue } \\
\hline & Non-Fragile $^{a}$ & Fragile \\
\hline \multicolumn{3}{|l|}{ Plows } \\
\hline Moldboard plow & $90-100$ & $95-100$ \\
\hline \multicolumn{3}{|l|}{ Chisel plows with: } \\
\hline Sweeps & $15-30$ & $40-50$ \\
\hline Straight spike points & $20-40$ & $40-60$ \\
\hline Twisted points or shovels & $30-50$ & $60-70$ \\
\hline \multicolumn{3}{|l|}{ Combination chisel plows } \\
\hline \multicolumn{3}{|l|}{ Coulter-chisel plow with: } \\
\hline Sweeps & $20-40$ & $50-60$ \\
\hline Straight spike points & $30-50$ & $60-70$ \\
\hline Twisted points or shovels & $40-60$ & $70-80$ \\
\hline \multicolumn{3}{|l|}{ Disk-chisel plow with: } \\
\hline Sweeps & $30-40$ & $50-70$ \\
\hline Straight spike points & $40-50$ & $60-70$ \\
\hline Twisted points or shovels & $50-70$ & $70-80$ \\
\hline \multicolumn{3}{|c|}{ Field cultivators (including leveling) } \\
\hline \multicolumn{3}{|c|}{ Field cultivator as primary tillage } \\
\hline Sweeps $30-50 \mathrm{~cm}$ wide & $10-20$ & $25-45$ \\
\hline Sweeps or shovels $15-30 \mathrm{~cm}$ & $20-30$ & $30-50$ \\
\hline Duckfoot points & $30-40$ & $45-70$ \\
\hline \multicolumn{3}{|c|}{ Row cultivators $76 \mathrm{~cm}$ wide rows } \\
\hline Single sweep per row & $10-25$ & $30-45$ \\
\hline Multiple sweeps per row & $15-25$ & $35-45$ \\
\hline Finger wheel cultivator & $25-35$ & $40-50$ \\
\hline Rolling disk cultivator & $45-55$ & $50-60$ \\
\hline Ridge till cultivator & $60-80$ & $75-95$ \\
\hline \multicolumn{3}{|l|}{ Row planters } \\
\hline \multicolumn{3}{|l|}{ Conventional planters with } \\
\hline Runner openers & $5-15$ & $10-20$ \\
\hline Staggered disk openers & $5-10$ & $5-15$ \\
\hline Double disk openers & $5-15$ & $15-25$ \\
\hline \multicolumn{3}{|l|}{ No till planters with } \\
\hline Smooth coulters & $5-15$ & $10-25$ \\
\hline Ripple coulters & $10-25$ & $15-30$ \\
\hline Fluted coulters & $15-35$ & $20-45$ \\
\hline
\end{tabular}

${ }^{a}$ Non-fragile residues are generally more difficult to incorporate due to their large size, greater resistance to breakage and decomposition (i.e. maize and wheat) in contrast to fragile residues that are relatively small and easily incorporated (soybean and peanuts). oration. The maximum amount of water that can be retained by crop residues is proportional to the mass of the residues. Dadoun (1993) noted that residues were shown to hold water up to 3.8 times their dry weight. The amount of precipitation intercepted is a function of the amount of water currently held and the maximum amount that can be retained by the residues. All of the water held by residues is assumed to be available for evaporation. The energy available for soil evaporation (i.e. soil potential evaporation) is budgeted for two processes: evaporation of water from residue; and evaporation of water from the soil. The soil potential evaporation (EOS, $\mathrm{mm}$ ) is decreased by the amount of water evaporating from the residues and the residue water content is updated.

2.2.3 Effects on soil parameters. Because biological activity is a function of temperature, and leaves, stems and reproductive organs are differentiated in the meristem, meristematic temperature should be used in thermal time calculation to more accurately predict attainment of biological stages. SALUS predicts plant development rate using the model developed by Vinocur and Ritchie (2001) to predict meristematic temperature from soil and air temperature to predict the phenology in early stages of plant development when the meristem of the plant is $1-2 \mathrm{~cm}$ below the soil surface (i.e. in maize and wheat). In light of the previous consideration, SALUS includes the Vinocur and Ritchie (2001) modification of the soil temperature model of CERES to account for the presence of crop residues.

The four soil properties in the model that vary with tillage are bulk density $\left(\mathrm{g} \mathrm{cm}^{-3}\right)$, satu-

Table 2. Values of average mass to area conversion for residue.

\begin{tabular}{lll}
\hline Crop & $\begin{array}{l}\text { Am } \\
(\text { ha kg-1) }\end{array}$ & Source \\
\hline Maize & 0.00032 & Van Doren and Allmaras, 1978 \\
Maize & 0.00040 & Gregory, 1982 \\
Wheat & 0.00054 & Gregory, 1982 data from Wishmeier et al., 1978 \\
Winter wheat stem & 0.00027 & Greb, 1967 \\
Wheat & 0.00045 & Gregory, 1982 \\
Winter wheat stems & 0.00027 & Greb, 1967 \\
Soybean & 0.00032 & Gregory, 1982 \\
Grain sorghum stems & 0.00006 & Greb, 1967 \\
Sunflower & 0.00020 & Gregory, 1982 \\
\hline
\end{tabular}


rated hydraulic conductivity $\left(\mathrm{cm} \mathrm{day}^{-1}\right)$, ponding capacity, and water content at saturation $\left(\mathrm{cm}^{3}\right.$ $\mathrm{cm}^{-3}$ ). Soil conditions after tillage are inputs and dynamically changed when precipitation occurs. The process of change in bulk density, saturated hydraulic conductivity follows the same pattern. The parameter changes from an initial value to a settled value following an exponential curve that is a function of cumulative rainfall kinetic energy since the last tillage operation:

$$
\begin{gathered}
\text { Xvar }=\text { Xstl }+(\text { Xtill }- \text { Xstl }) * \\
\text { EXP }(- \text { RSTL } * \text { SUMKE })
\end{gathered}
$$

where Xvar represents the dynamic soil property, Xtill is its value just after a tillage operation, Xstl is the settled value of the property, RSTL is the rate of change of the soil property (per $\mathrm{J} \mathrm{cm}^{-2}$ of rainfall kinetic energy), and SUMKE is the cumulative rainfall kinetic energy since the last tillage operation $\left(\mathrm{J} \mathrm{cm}^{-2}\right)$. The rate of change of the soil property is assumed to be a function of soil water aggregate stability (AS, 0.0-1.0). Water aggregate stability (AS) is correlated to soil organic matter (Tisdall and Oades, 1982):

$$
\begin{aligned}
& \mathrm{AS}=0.005 * \text { OC }(\mathrm{L}) \\
& \mathrm{RSTL}=10 *(1-\mathrm{AS})
\end{aligned}
$$

where $\mathrm{OC}(\mathrm{L})$ is the percentage organic carbon content of soil layer L. Aggregate stability is not measurable in absolute terms. It expresses the resistance of aggregates to breakdown when subjected to disruptive processes such as intermittent rainfall. Eq. (3) normalizes the value of aggregate stability such that a value of 1.0 represents the greatest stability while a value of 0.0 represents soil aggregates that have absolutely no resistance to destructive forces. A relationship was used to estimate cumulative rainfall kinetic energy from cumulative precipitation (Wishmeier et al. 1978).

$$
\begin{gathered}
\mathrm{KE}=3.812+0.812 * \operatorname{Ln}(\mathrm{RAIN} / \mathrm{TIME}) \\
* \text { RAIN }
\end{gathered}
$$

Surface cover (SOILCOV) from residue (FC) and crop canopy (CANCOV) decreases the amount of energy received by the soil surface proportionally to the surface covered (Wishmeier et al., 1978).

$$
\begin{gathered}
\text { SOILCOV }=\text { CANCOV }+ \text { FC * } \\
(1-\text { CANCOV })
\end{gathered}
$$

Effect of the rainfall intensity decreases with soil depth. The decrease of the effect was assumed exponential with depth (depth, cm) and the coefficient used, 0.15 cancels the intensity at the bottom of the tilled layer $(26 \mathrm{~cm})$. Hence the cumulative intensity is calculated for the top four layers.

$$
\begin{gathered}
\text { SUMKE }(\mathrm{L})=\sum(1-\text { SOILCOV }) \\
\operatorname{KE}^{*} \operatorname{EXP}\left(-0.15^{*} \text { depth }\right)
\end{gathered}
$$

Every time bulk density changes, the saturation water content for each layer L (SAT(L)) is updated using the equation relating porosity and density:

$$
\operatorname{SAT}(\mathrm{L})=0.92 *(1-\mathrm{BD}(\mathrm{L}) / 2.66)
$$

where $\mathrm{BD}(\mathrm{L})$ is the bulk density of layer $\mathrm{L}(\mathrm{g}$ $\mathrm{cm}^{-3}$ ), soil particle density is assumed to be 2.66 $\mathrm{g} \mathrm{cm}^{-3}$, and $92 \%$ of the total porosity is assumed to be effective due to air entrapment (Dadoun, 1993).

Field study: tillage systems effects on infiltration and time to ponding

To estimate both runoff and loss of soil through erosion and to provide a rational basis for predicting infiltration during rainfall or irrigation it is crucial to predict the "time-to-ponding". Time-to-ponding is defined as the time (during rainfall or sprinkler irrigation) when free water first appears at the soil surface (White et al., 1989). This time defines the period beyond which both runoff and erosion may occur. The study was conducted on a silty loam soil without plants at the CIMMYT (International Centre for Maize and Wheat Improvement) $\mathrm{El}$ Batan experimental station in central Mexico.

The treatments compared in this study were conventional tillage (moldboard at $25 \mathrm{~cm}$ followed by scarifying at $15 \mathrm{~cm}$ ), minimum tillage (moldboard at $15 \mathrm{~cm}$ ) and no-tillage. The study was conducted on a plot that had been under no-tillage for 8 years. The conventional and minimum tillage treatments were imposed on this plot for a direct comparison of surface management.

Water was applied with sprinkler irrigation at various rates that would never allow any surface ponding. The infiltration rate was calculated by multiplying the infiltration amount and the time necessary for the water to infiltrate in 
the soil. The application of water was terminated when the infiltration rate was equal to the saturated hydraulic conductivity present at a deeper soil layer.

Estimates of the time-to-ponding were determined using the equation currently used in the SALUS water balance model (Ritchie et al., 2005). The time-to-ponding determines the precipitation rate above which water ponds, which is equivalent to the maximum infiltration rate. Precipitation that cannot infiltrate, ponds. When ponding exceeds the ponding capacity of the soil, water runs off. Ponding also activates the soil surface macropores.

The water application system produced a uniform wetted area $4 \mathrm{~m}$ wide by $4 \mathrm{~m}$ long. The uniformity of the water application system was checked by placing 10 tin cup $(2 \mathrm{~cm}$ high by 5 $\mathrm{cm}$ i.d.) on the measured area and by collecting the water at the end of each applications.

\subsection{Simulation study: simulated effects on soil biophysical properties}

The soil organic carbon dynamic was simulated using a 50-year weather record from a meteorological station in Foggia and a clay soil type. The simulated tillage effects on $\mathrm{CO}_{2}$ evolution, bulk density, drainage, soil evaporation and runoff was performed using 15 year weather records from a field in San Basilio, Ro, NE Italy. The soil used in the latter simulation study was a loamy soil with medium content of organic matter $(1.5 \%)$.

\section{Results and discussion}

\subsection{Infiltration and time-to-ponding}

The time to observe the presence of free water on the soil surface is function of the surface management and thus it varied between treatments. The no tillage treatment with residues retained on the surface showed the highest infiltration (Figure 2). Crop residues increased infiltration for all the treatments compared to soil surface without residues. The lowest infiltration was observed in the conventional tillage systems without residues. Ponding conditions were observed for this treatment after 25 minutes of irrigation with only $2 \mathrm{~cm}$ of water infiltrated.

Figure 3 shows the infiltration rates with respect to the cumulative infiltration. The infiltra-

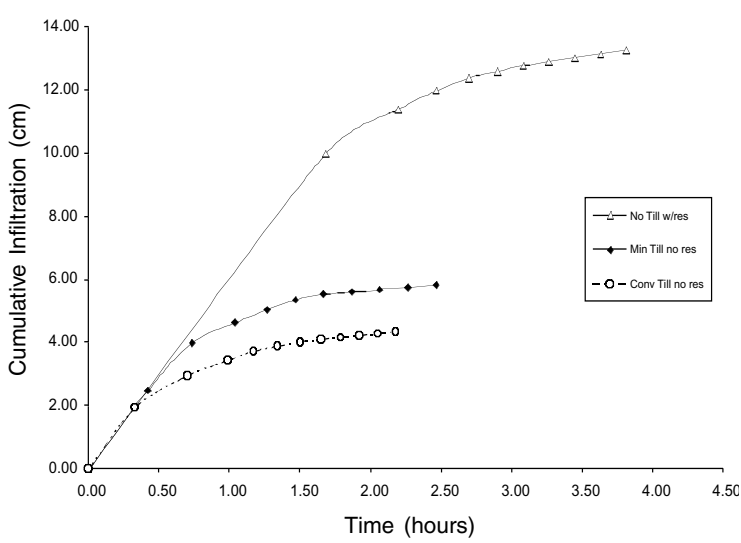

Figure 2. Cumulative infiltration for the tillage systems at CIMMYT experimental station El Batan, Mexico.

tion rate follows an exponential decay with the final rate controlled by the saturated hydraulic conductivity of the deeper layer. The KSAT of the lower layers slows the infiltration and if the rate of the water application is higher than the value of KSAT of the restricting layer, the water backs up through the soil layers consequently decreasing the infiltration rate. This can be observed by the change in the exponential curve that occurs when the infiltration approaches the final rates (see arrows on figure 4). The lower slope of the exponential curve approaching the KSAT of the lower layer is confirmed by the theory (Broadbridge and White, 1987; Broadbridge et al., 1988, White et al., 1989). In their study, Broadbridge et al. (1988), illustrated the theoretical differences in the base-

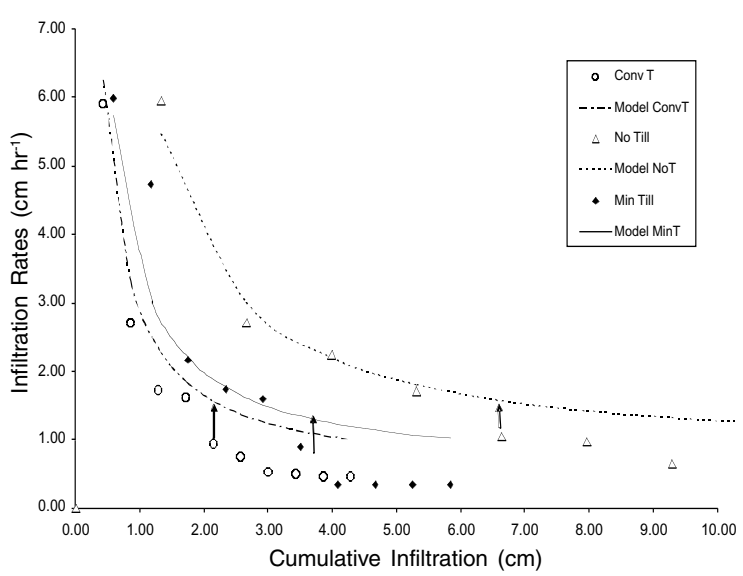

Figure 3. Measured and simulated values for the time-toponding curve of the three tillage systems at CIMMYT experimental station El Batan, Mexico. 


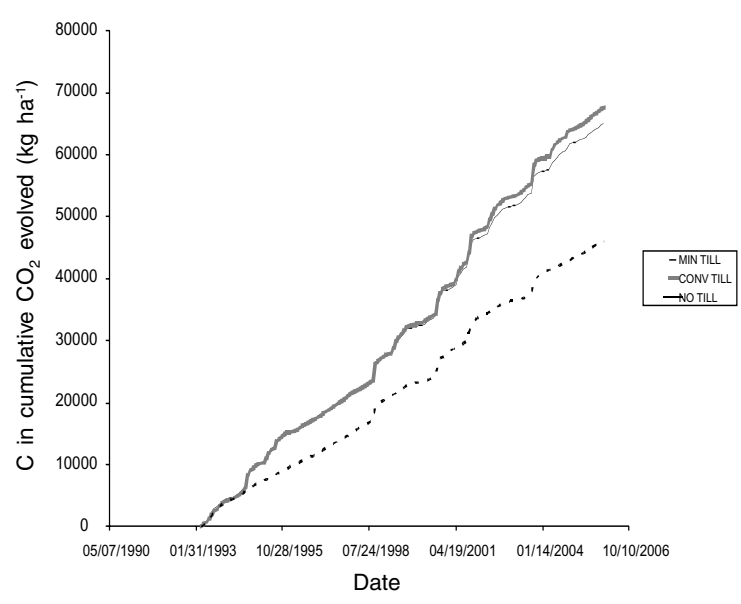

Figure 4. Simulated carbon in cumulative $\mathrm{CO}_{2}$ evolved from a loamy soil under different different tillage systems (San Basilio, Ro, Italy).

ment moisture build-up. They reported that when the rainfall rate exceeds the surface infiltration rate, surface ponding precedes basement saturation; when, instead, the rainfall rate is less then the critical value for the surface infiltration rate, basement saturation precedes surface ponding. In this case, the time to basement saturation is close to the time taken for the rainfall to fill the available pore space. This phenomenon was confirmed by this study for all the treatment in comparison. Indeed, looking at the no tillage treatment (Figure 3) as an example, the exponential curve for the time-to-ponding changes slope at the infiltration rate of $1.7 \mathrm{~cm}$ $\mathrm{hr}^{-1}$. If the curve were to keep the same slope, the successive infiltration rate would have been at $1.6 \mathrm{~cm} \mathrm{hr}^{-1}$ instead of 1.1 as a result of the KSAT of the restricting soil layer. The dashed lines represent the KSAT of the deeper layer. The model was used to simulate time to ponding under different rates. The model provided satisfactory results for all the treatments till the KSAT of lower layer was reached. In order to include the effect of the KSAT of a deeper layer, a complete water balance is necessary.

\subsection{Simulation of tillage effects on soil organic carbon}

The simulation results of the SALUS model estimating the effect of the conventional tillage, minimum tillage and no tillage on the carbon lost from the soil surface as carbon dioxide $\left(\mathrm{CO}_{2}\right)$ are presented in figure 4 . The no tillage

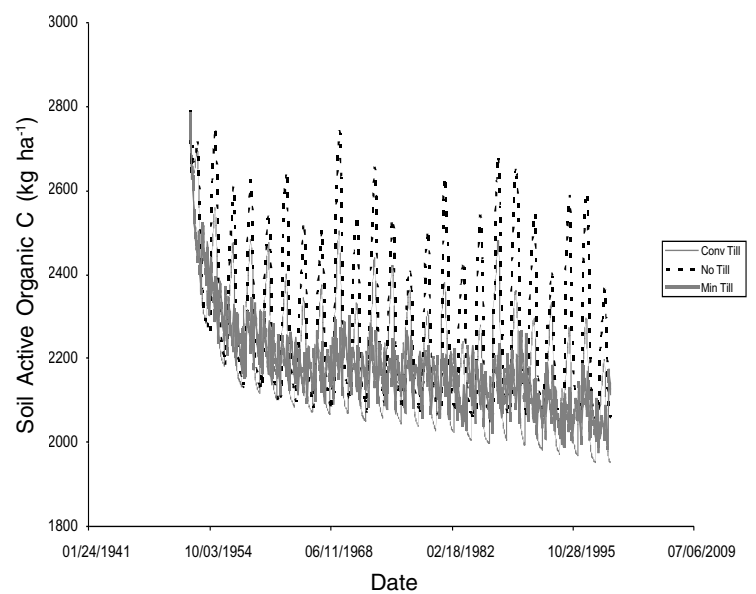

Figure 5. Long-term simulated soil active organic carbon from a clay soil under different tillage systems (Foggia, Italy).

clearly showed a reduction in $\mathrm{C}$ losses through $\mathrm{CO}_{2}$ as expected due to a lower soil mineralization and higher accumulation of organic matter. For the simulated period of 15 years, the no tillage treatment sequestered in the soil about $20000 \mathrm{~kg} \mathrm{ha}^{-1}$ of carbon compared to the minimum and conventional tillage treatment. No significant differences were observed between the two tilled treatments. Tillage practices disturb soil structure causing fracturing which increases the movement of $\mathrm{CO}_{2}$ out of the soil and oxygen into it. Similar results were found by various authors (Reicosky et al., 1995; Lal, 1997; Lal, 2004a). In this specific case, the reduction of $\mathrm{CO}_{2}$ emissions in the no tillage systems converts into an increase in carbon storage which builds organic matter and long-term productivity.

The trend of the simulated carbon pool decomposition by SALUS are shown in figure 5 and 6 . The soil active organic carbon (Figure 5) confirmed the theory which sees the no tillage treatment the most efficient from this point of view with a slower decomposition rate, in addition to the carbon sources provided by the stubble retained on the soil surface. Figure 6 combines the simulated results of the resistant and slow carbon pool. Also in this case, the no tillage systems showed to be the best treatment for soil carbon storage with consequent behavior of sink instead of source for both pools. The soil resistant organic carbon requires a long term period to detect any changes. The simulated results of SALUS are in line with what found by 


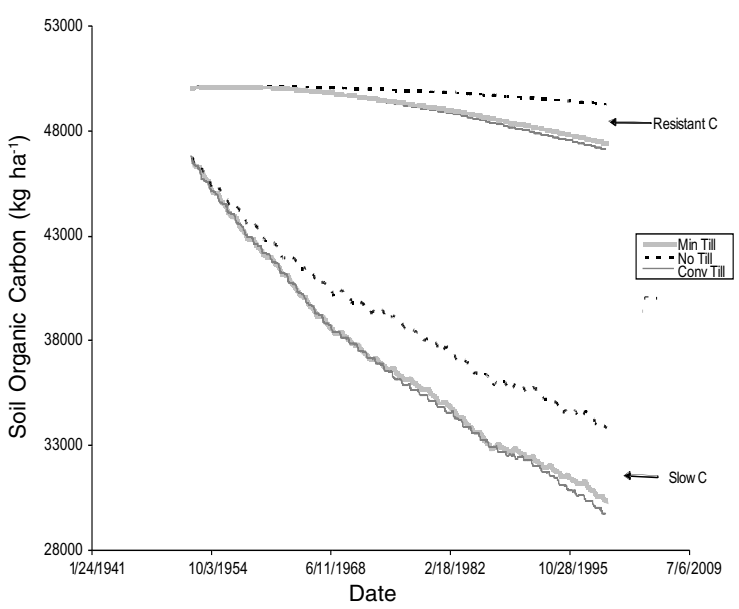

Figure 6. Long-term simulated soil resistant and slow organic carbon from a clay soil under different tillage systems (Foggia, Italy).

previous authors (Lal, 2004a). Small changes are observed in the continuous conventional and minimum tillage with their associate stubble removal. The simulated results represent a simulation run of 52 years of wheat grown in Foggia, southern Italy.

\subsection{Simulation of tillage effects on soil water bal- ance variables}

Figure 7 through 11 show the simulated behavior of soil properties in a loamy soil of San Basilio, a rural area close to Rovigo, Italy, affected by the tillage systems compared in the model scenarios. Simulated changes in bulk density (Figure 7a) were due to tillage operations first with a decrease and increase there after due to the rainfall kinematic energy. To clearly illustrate the effect of tillage on bulk density, only the conventional tillage is shown. Figure $7 \mathrm{~b}$ depicted the effect of different tillage systems on the $7-15 \mathrm{~cm}$ layer. The behavior of the surface property, as depicted by the model, were consistent with general expectations described by Mankin et al., 1996. Bulk density of the top layer decreased due to loosening of the soil, but it returned to the original value with the occurrence of rainfall. Similar trend were also observed for the layers where tillage occurred (7-15 and $15-26 \mathrm{~cm})$. The conventional tillage causes an increased reduction of bulk density compared to minimum tillage effect.

Figure 8 showed the cumulative drainage

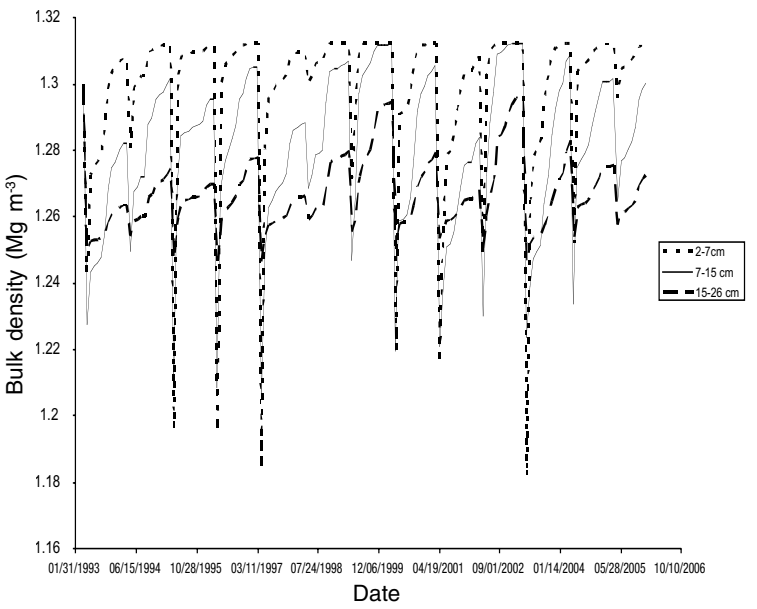

Figure 7a. Simulated effect of conventional tillage on bulk density for the layers 2-7 cm; 7-15 cm; (San Basilio, Ro, Italy).

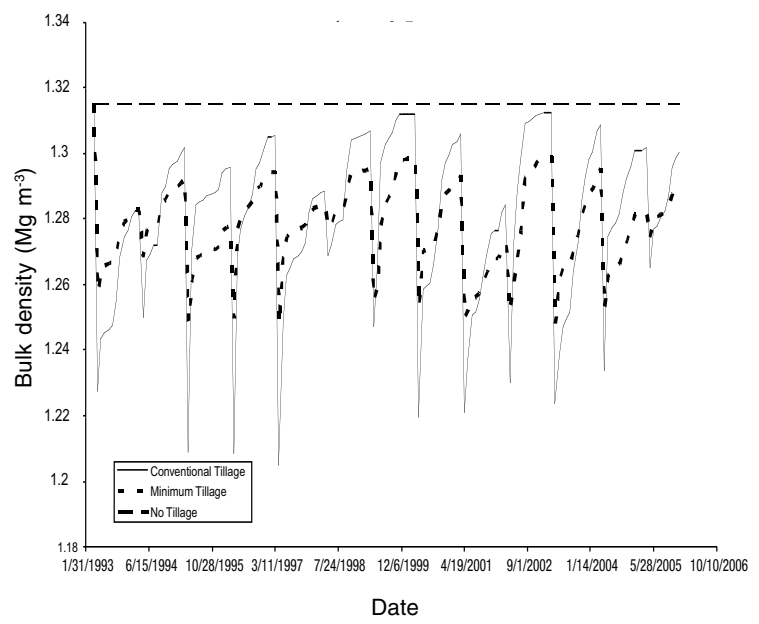

Figure $7 \mathrm{~b}$. Simulated effect of different tillage systems on bulk density from a loamy soil (San Basilio, Ro, Italy).

simulated for the three tillage systems. The no tillage treatment showed the highest amount of drainage as expected due to the presence of a better soil structure and porosity. This phenomenon is also a result of the additional water that infiltrates due to the presence of residues on the soil surface that reduce the kinetic energy of the rainfall. Conventional tillage was the treatment with the lowest amount of water draining through the soil profile, due to higher surface runoff as well as increase in water storage.

The reduction in soil evaporation was clearly evident under no tillage (Figure 9), with 300 $\mathrm{mm}^{-1}$ being the standard evaporation for the studied environment. The presence of residues 


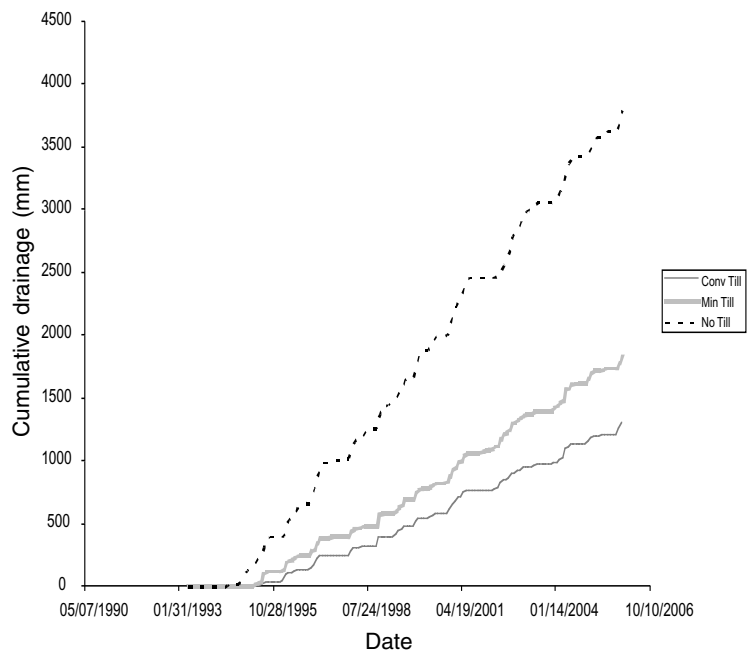

Figure 8. Simulated cumulative drainage from a loamy soil under different tillage systems (San Basilio, Ro, Italy).

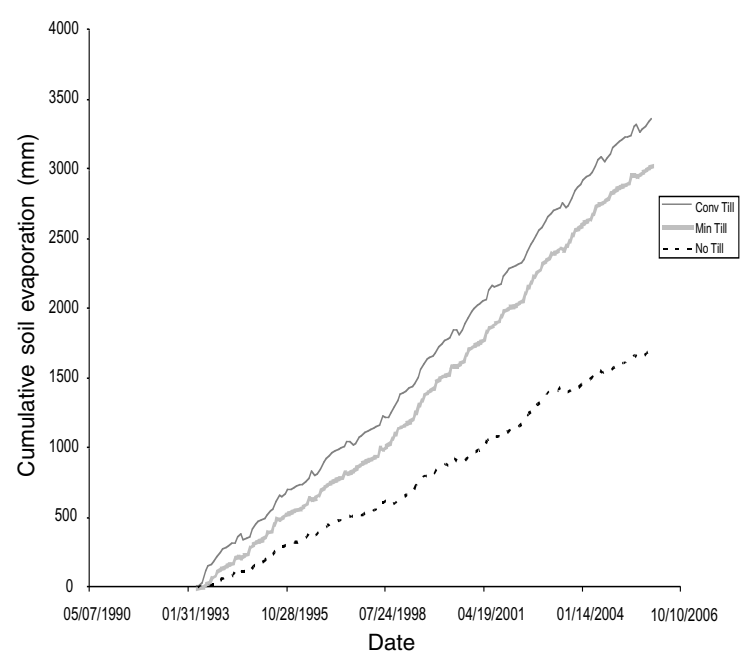

Figure 9. Simulated cumulative soil evaporation from a loamy soil under different tillage systems (San Basilio, Ro, Italy).

on the soil surface in the no tillage systems reduced the loss of water from the soil surface. Additional information to explain these differences between tillage treatment reside in the soil water content data of the top layer (data not shown). Riley et al. (1994) reported a reduction of soil evaporation in the treatment where plant residues were retained on the surface. Throughout the season and for other locations (Dadoun, 1993; Andales et al., 2000) soil water content in top $15 \mathrm{~cm}$ was greater in the no tillage systems compared to conventional and minimum tillage.

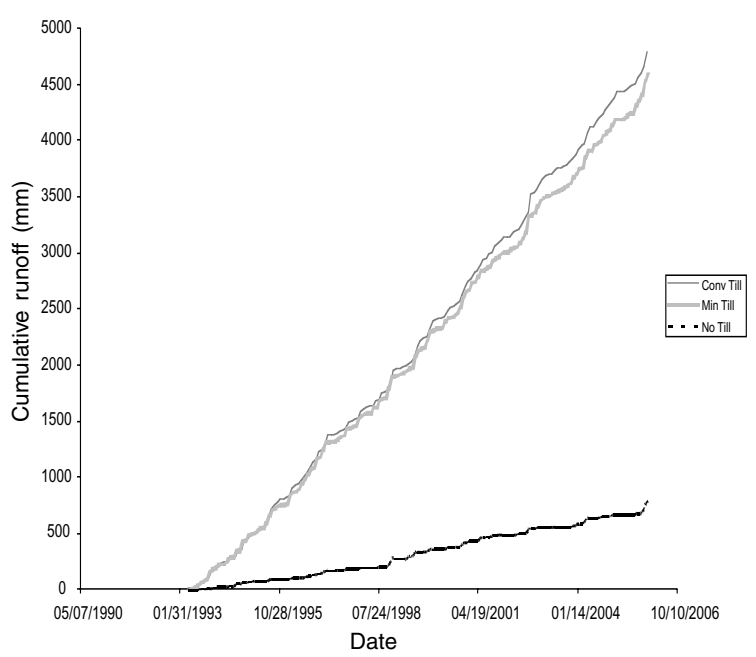

Figure 10. Simulated cumulative runoff from a loamy soil under different tillage systems (San Basilio, Ro, Italy).

Cumulative runoff (Figure 10) was greater in the conventional tillage and least in the no tillage systems. Surface crop residues increased the amount of infiltration in the no tillage systems (as shown in the CIMMYT study) by reducing the kinematic energy of the rain and, due to higher surface roughness). Conservation tillage management with surface residue accumulation has been shown to reduce runoff by buffering the soil surface against rainfall impact (Langdale et al., 1992). Soil structure in the no tillage system, with the undisturbed presence of earthworm channels and previous root canals allow for a better distribution in the deep layer compared to the conventional tillage that in many case is associated with an hard pan (low conductivity layer) cause by the compaction of tillage (Rasmussen, 1999). Saturated flow of water through large pores and cracks, quickly reaches the compacted layer in conventional tillage causing saturation overland runoff (Basso, 2000; Franzluebbers, 2002).

The difference between tillage and no tillage systems in regard to simulated runoff depicted in figure 10 are substantial demonstrating that no tillage system should be advised in areas with high intensity rainfall.

\section{Conclusions}

Improper use of crop residues (e.g. removal, buring, or plowing under) can accelerate soil 
degradation process through soil erosion, depletion of soil fertility and environmental pollution of surface and groundwater contamination. Residue management and conservation tillage system improves soil structure, enhance soil fertility, sequester carbon and mitigate greenhouse effect. The experiment to estimate the time to ponding curve under different tillage system confirmed the theory and shows the beneficial effects of the residue on soil surface with respect to water infiltration. It also showed that the no-tillage system is a more appropriate system to adopt in areas characterized by high intensity rainfall.

The paper described the application of SALUS model, a dynamic model that simulate the effects of management on the soil-plant-atmosphere system. In this study, its tillage component was presented and the effects of tillage systems and residues management were simulated on some biophysical soil properties. The simulated results confirmed the theory and what was found in field studies conducted by previous authors. The no tillage system proved to be the practice that sequestered more carbon and increase water infiltration through the reduction of soil evaporation and runoff.

\section{References}

Andales A.A., Batchelor W.D., Anderson C.E., Farnham D.E., Whigham D.K. 2000. Incorporating tillage effects into a soybean model. Agric. Systems, 66 69:9.

Allmaras R.R., Hallauer E.A., Nelson W.W., Evans S.D. 1977. Agric. Ext. Stn.Techn. Bull. n. 306. St. Paul, Minn.

Arrue J.L. 1997. Effect of conservation tillage in the CO2 sink effect of the soil. In: García-Torres L. GonzálezFernández P. (eds.): Conservation agriculture: agronomic, environmental and economic bases (in Spanish), 189-200. Spanish Association for Conservation Agriculture (AEAC/ SV), Cordoba, Spain.

Ball B.C., Tebrügge F., Sartori L., Giraldez J.V., Gonzalez P. 1998. Influence of no-tillage on physical, chemical and biological soil properties. In: Tebrügge F., Böhrnsen A. (eds.): Experiences with the applicability of no-tillage crop production in the west-European countries, 7-27. Final report of Concerted Action n. AIR 3 - CT 93-1464. Fachverlag Köhler, Giessen.

Basso B. 2000. Digital terrain analysis and simulation modeling to assess spatial variability of soil water balance and crop production. Ph.D. Dissertation. Michi- gan State University, East Lansing, MI, USA. 174 pp.

Basso B. 2003. Perspectives of precision agriculture in conservation agriculture. In: Garcia Torres L., Benitez J., Martinez Vilela A. (eds.): Conservation agriculture, 255-262. Kluwer.

Basso F., Pisante M., Basso B. 1996. Influenza dei residui colturali e delle lavorazioni sull'umidità del terreno, sull'accrescimento e produzione del favino da seme (Vicia Faba Minor Beck) e frumento duro (Triticum Durum Desf.). Riv. Agron., 3:212-221.

Basso F., De Franchi A.S., Pisante M., Basso B., Landi G. 2000. Influenza della modalità di lavorazione del terreno sul processo erosivo e sulla produzione di sistemi colturali nella collina meridionale. Riv. Agron., 34:296-305.

Basso F., Pisante M., Basso B. 2002. Chapter 25: Soil erosion and land degradation. In: N.A. Geeson, C.J. Brandt, J.B. Thornes (eds.): Mediterranean desertification: A mosaic of processes and responses, 347-359. John Wiley \& Sons Ltd.

Batchelor W.D., Basso B., Paz J.O. 2002. Examples of strategies to analyze spatial and temporal yield variability using crop models. Eur. J. Agron., 18:141-158.

Borin M., Menini C., Sartori L. 1997. Effects of tillage systems on energy and carbon balance in north-eastern Italy. Soil \& Tillage Research, 40:209-226.

Bouma J. 2002. Land quality indicators of sustainable land management across scales. Agriculture, Ecosyst. and Environ., 88:129-136.

Broadbridge P., White I. 1987. Time-to-ponding: Comparison of analytic, quasi-analytic and approximate predictions. Water Resour. Res., 23:2302-2310.

Broadbridge P., Knight J.H., Rogers C. 1988. Constant rate rainfall infiltration in a bounded profile: Solutions of a nonlinear model. Soil Sci. Soc. Am. J., 52:1526-1533.

Buckingham F., Pauli A.W. 1993. Tillage. Fundamentals of machine operation. Deere and Company, Moline, IL, p. 158.

Cole C.V. 1996a. Agricultural options for mitigation of greenhouse gas emissions. In: Climate change 1995: Impacts, adaptation and mitigation of climate change: Scientific technical analyses, Chapter 23, 745-771. IPCC Working Group II, Cambridge University Press, UK.

Cole C.V. 1996b. Intergovernmental panel on climate change. 1995. Agricultural options for mitigation of greenhouse gas emissions IPCC Workgroup II. Chapter 23, Washington, DC.

Davidson E.A., Ackerman I.L. 1993. Changes in soil carbon inventories following cultivation of previously untilled soils. Biogeochemistry, 20:161-193.

European Environment Agency 1998. Soil Degradation, chapter 11, 231-246; chapter 2, Climate change, 3759. In: Europe's environment: The second assessment. Elsevier Science Ltd.

Dadoun F.A. 1993. Modeling tillage effects on soil phys- 
ical properties and maize development and growth. Ph.D. Thesis, Michigan State University, MI.

Franzluebbers A.J. 2002. Water infiltration and soil structure related to organic matter and its stratification with depth. Soil and Tillage Res., 66:197-205.

Greb B.W 1967. Percent soil cover by six vegetative mulches. Agron. J., 59:610-611.

Gregory J.M. 1982. Soil cover prediction with various amounts and type of crop residue. Trans. ASAE 13331337.

Griffith D.R., Mannering J.V., Modenhauer W.C. 1977. Conservation tillage in Eastern corn belt. J. Soil Water Conserv., 32:20-29.

Kyoto Protocol/ United Nations. 1998. Framework Conventions on climate change, http://www.unccc.org.

Jones J.W., Ritchie J.T. 1991. Crop growth models. In: Hoffman G.J., Howell T.A., Soloman K.H. (eds.). Management of farm irrigation systems. ASAE, St. Joseph, MI.

Lal R. 1997. Residue management, conservation tillage and soil restoration for mitigating greenhouse effect by CO2-enrichment. Soil \& Tillage Research., 43(12):81-107.

Lal R. 2004. Soil Carbon Sequestration Impacts on Global Climate Change and Food Security. Science, 604, 1623-1627.

Lal R. 2004. Managing Soil Carbon. Science 304, 393.

Langdale G.W., West L.T., Bruce R.R., Miller W.P., Thomas A.W. 1992. Restoration of eroded soil with conservation tillage. Soil Technol., 5:81-90.

Mankin K.R., Ward A.D., Boone K.M. 1996. Quantifying changes in soil physical properties from soil and crop management: a survey of experts. Transactions of the ASAE 39 (6):2065-2074.

Paustian K., Cole CV., Sauerbeck D., Sampson N. 1998. $\mathrm{CO} 2$ mitigation by agriculture: An overview. Climatic Change, 40:135-162.

Rasmussen K.J. 1999. Impact of ploughless soil tillage on yield and soil quality: A Scandinavian review. Soil \& Tillage Res., 53:3-14.

Rasmussen P.E., Goulding K.W.T., Brown J.R., Grace P.R., Janzen H.H., Korschens M. 1998. Long-term agroecosystem experiments: Assessing agricultural sustainability and global change. Science, 282:893896.

Reeves D.W. The role of soil organic matter in maintaining soil quality in continuous cropping systems. Soil and Tillage Res., 43:131-167.

Recisosky D.C., Cassel D.K., Blevins R.L., Gill W.R., Naderman G.C. 1977. Conservation tillage in the southeast. J. Soil Water Conserv., 32:13-20.

Reicosky D.C. 1995. Impact of tillage on soil as a car- bon sinkIn: Farming for a better environment. A White Paper, 50-53. Soil and Water Conservation Society, Ankeny, Iowa, USA.

Reicosky D.C., Kemper W.D., Langdale G.W., Douglas Jr. C.L., Rasmussen P.E. 1997. Soil organic matter changes resulting from tillage and biomass production. J. Soil Water Conserv., 50:253-262.

Riley H., Bùrresen T., Ekeberg E., Rydberg T. 1994. Trends in reduced tillage research and practice in Scandinavia. In: Carter M.R. (ed.): Cons. Till. in Temp. Agroecosystems, 23-45. Lewis Publishers.

Ritchie J.T., Godwin D.C., Otter-Nacke S. 1985. CERESWheat: A simulation model of wheat growth and development. Texas A\&M University Press, College Station, TX.

Ritchie J.T., Singh U., Godwin D.C., Hunt L. 1989. A user's guide to CERES Maize-V.2.10. Muscle Shoals, AL. International Fertilizer Development Center.

Ritchie J.T., Basso B., Gerakis A., White I. 2005. Incorporating seasonal rainfall intensity and soil properties into a daily surface runoff model. Agronomy Abs.

Salus software. System Approach for Land Use Sustainability, http://salus.gis.fcu.edu.tw.

Robertson G.P., Paul E.A., Harwood R.R. 2000. Greenhouse gases in intensive agriculture: Contributions of individual gases to the radiative forcing of the atmosphere. Science, 289:1922-1925.

Shelton D.P., Dickey E.C., Jasa P.J. 1990. Estimating percent residue cover. In: E.C. Dickey, Jasa P.J. (ed.): Conservation tillage proceeding $\mathrm{n}$. 9. University of Nebraska, Cooperative extension, Nebraska.

Smith P., Powlson DS., Glendining MJ., Smith JU. 1998. Preliminary estimates of the potential for carbon mitigation in European soils through no-till farming. Global Change Biology, 4:679-685.

Tisdall J.M., Oades J.M. 1982. Organic matter and water stable aggregates. J. Soil Sci., 33:141-163.

Van Doren Jr. D.M, Allmaras R.R. 1978. Effect of residue management on the soil physical environment, microclimate and plant growth. In: Oschwald W.R. (ed.): Crop residue management systems. Houston, Texas, Nov. 28-Dec 3, 1976. ASA-CSSA-SSSA, Madison WI, USA.

Vinocur M., Ritchie J.T. 2001. Maize leaf development biases caused by air-apex temperature differences. Agron. J., 93:767-772.

White I., Sully M.J., Melville M.D. 1989. Use and hydrological robustness of Time-to-incipient-ponding. Soil Sci. Soc. Am. J., 29:1343-1346.

Wishmeier W.H., Smith D.D. 1978. Predicting rainfallerosion-a guide to conservation planning. USDA Agriculture Handbook 537. 